Portland State University

PDXScholar

$5-27-2017$

\title{
Increasing Engagement on Nonprofit Facebook Pages through Photos
}

Christina T. Guiang

Portland State University

Follow this and additional works at: https://pdxscholar.library.pdx.edu/honorstheses Let us know how access to this document benefits you.

\section{Recommended Citation}

Guiang, Christina T., "Increasing Engagement on Nonprofit Facebook Pages through Photos" (2017). University Honors Theses. Paper 396.

https://doi.org/10.15760/honors.392

This Thesis is brought to you for free and open access. It has been accepted for inclusion in University Honors Theses by an authorized administrator of PDXScholar. Please contact us if we can make this document more accessible: pdxscholar@pdx.edu. 


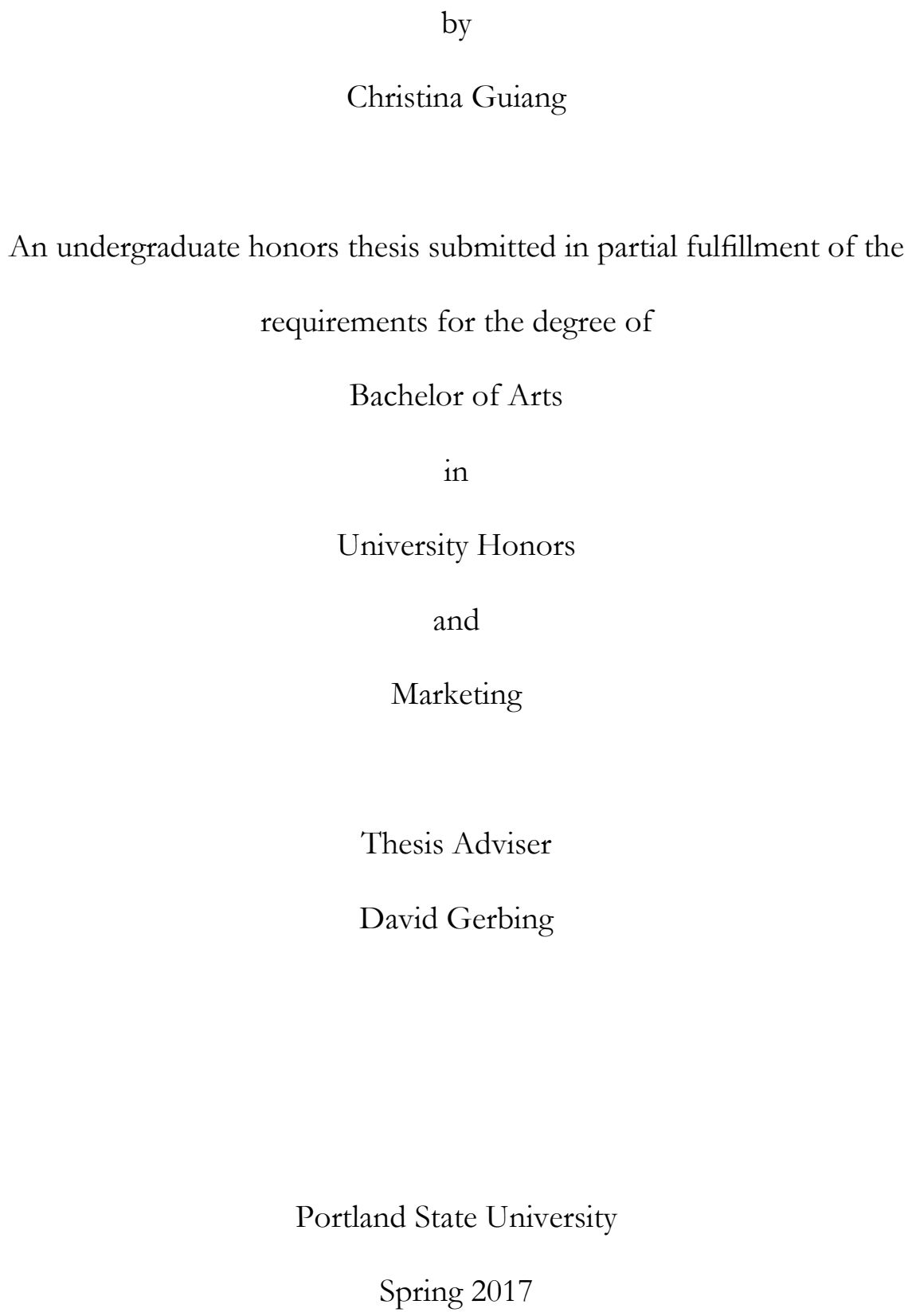




\begin{abstract}
Social media has become an immensely valuable tool for nonprofit marketing strategies. Social media platforms such as Facebook and Twitter provide free tools for nonprofit organizations to spread awareness, build their organizational identity, communicate with their stakeholders, and inspire action and involvement. These outlets have therefore, for many organizations, become an essential component of their marketing communications. Developing effective strategies that maximize social media post engagement is beneficial in aiding organizations to achieve their marketing goals. This study focuses specifically on Facebook photo posts due to the platform's widespread use and the high potential of visual media to provoke audience engagement, and aims to identify effective strategies for combining various text functions and types of photo content in order to maximize engagement from followers.
\end{abstract}


PHOTOS

\section{TABLE OF CONTENTS}

$\begin{array}{ll}\text { Literature Review } & 4\end{array}$

Nonprofit Use of Social Media $\quad 4$

Content Analysis of Photo Posts on Facebook 5

$\begin{array}{ll}\text { Methodology } & 6\end{array}$

Data Collection 6

$\begin{array}{ll}\text { Coding } & 7\end{array}$

Analysis 9

$\begin{array}{ll}\text { Results } & 10\end{array}$

Discussion \& Conclusions 11

Limitations \& Further Research 12

$\begin{array}{ll}\text { References } & 15\end{array}$

$\begin{array}{ll}\text { Appendix } & 17\end{array}$ 

PHOTOS

\section{LiterATURE REVIEW}

\section{Nonprofit Use of Social Media}

Social media has become highly valuable for nonprofit marketing efforts as a cost-effective tool that allows organizations to engage with their stakeholders. In recent years, its use among nonprofit organizations has become increasingly widespread. A 2014 study found that about $87 \%$ of nonprofit advocacy organizations use Facebook, while nearly $80 \%$ use Twitter. 93\% of organizations use any social media tool (Guo \& Saxton, 2014). More in-depth research has been done to model how social media has been adopted by nonprofits (Campbell et al., 2014; Goldkind, 2015; Nah \& Saxton, 2012; Waters \& Feneley, 2013) and its perceived impact (DiStaso et al., 2011).

Extensive research has been done on how nonprofits use social media to achieve specific goals such as raising awareness (Davis et al., 2016), building their organizational identity (Waters \& Jones, 2011), engaging with stakeholders (e.g., Cho et al., 2014; Lovejoy et al., 2012; Waters et al., 2009), and inspiring action and involvement both online and offline (Paek et al., 2013; Palin et al., 2014). Content analyses have been conducted on social media platforms such as Facebook (e.g., Bortree \& Seltzer, 2009; Cho et al., 2014; Cho \& Schweickart, 2014; Huang et al., 2016; Saxton \& Waters, 2014), Twitter (Guo \& Saxton, 2014; Lovejoy et al., 2012; Lovejoy \& Saxton, 2012; Waters \& Jamal, 2011) and YouTube (Waters \& Jones, 2011) to discern what methods nonprofits use to achieve these goals and to assess their effectiveness. A Twitter content analysis was conducted in a 2012 study in which the Information-Community-Action scheme was developed for categorizing the functions of tweets from various nonprofit Twitter accounts, with informational use of the platform emerging as the most prevalent (Lovejoy \& Saxton, 2012). Subsequently, a content analysis of nonprofit Facebook posts that used the four models of public communication (developed by Grunig \& Hunt, 1984) similarly found that the one-way public information message strategy was the 
PHOTOS

most commonly implemented (Cho \& Schweickart, 2014). Some analyses have focused on specific nonprofit organizations or groups of organizations across multiple platforms, such as the American Red Cross (Briones et al., 2010), HIV/AIDS organizations (Huang et al., 2016), and environmental advocacy groups (Bortree \& Seltzer, 2009).

Content analyses have been conducted to evaluate social media message strategies and their relationship with engagement levels. On Facebook, post engagement is measured based on the numbers of likes (now under the category of reactions as of 2016), comments and shares. Using the Information-Communication-Action model, a 2014 study of nonprofit Facebook posts determined that dialogic messages received the most likes, while one-way informational messages received the most shares (Saxton \& Waters, 2014).

\section{Content Analysis of Photo Posts on Facebook}

Content analyses have yet to be conducted with a focus on photo posts. With nonprofit Facebook posts specifically, photos have the highest rate of engagement at 5.2\%, compared to $4.2 \%$ for video posts (“Benchmarks 2017,” 2017). It would be advantageous for nonprofits to develop effective strategies specifically for their photo posts, which could bring in more engagement on their pages overall and attract followers by expanding their reach. Optimizing their strategies would require an understanding of how best to combine various message strategies with different types of photo content to create posts that encourage maximum engagement levels. It is therefore worthwhile to determine correlations between photo post content and engagement trends.

Because of the sheer size of its network, Facebook represents a logical starting point for research of this kind. With over 1.87 billion active users and the highest growth rate of active users among all social media platforms in the past six years (Chaffey, 2017), as well as its more widespread adoption rate among nonprofit organizations (Guo \& Saxton, 2014), it is especially important to 
develop effective strategies for this platform. Additionally, posts on nonprofit Facebook pages tend to have significantly higher levels of engagement compared to their Twitter posts. On their Facebook pages, $4.6 \%$ of unique impressions garnered engagement, compared to only $1.3 \%$ for Twitter (“Benchmarks 2017,” 2017).

This study focuses on how nonprofits can increase engagement specifically on Facebook photo posts, and asks the following research questions:

RQ1: What is the relationship between engagement and the type of content of photo posts on humanitarian aid and disaster relief nonprofit organizations’ Facebook pages?

RQ2: Based on RQ1, how can nonprofits maximize engagement on their social media posts through the use of photos?

This study aims to apply the research that has been previously conducted on Facebook message strategies and supplement it with a proposed method for analyzing the effectiveness of these strategies in combination with various types of photo content, with effectiveness measured in the form of post engagements. Nonprofits within the field of humanitarian aid and disaster relief were chosen as the field of concentration for this study.

\section{METHODOLOGY}

\section{Data Collection}

Raw data was collected from three US-based nonprofit organizations' Facebook pages: Jordan International Aid (JIA), Project Concern International (PCI), and Mercy Corps. These three organizations all operate within the field of humanitarian aid and disaster relief, have a regularly maintained Facebook page, and incorporate photos into a portion of their posts. JIA has a smaller following of about 1.8 thousand followers; PCI and Mercy corps have larger followings, with about 
PHOTOS

109 thousand and 183 thousand followers, respectively (as of April 2017). Data was extracted from JIA and PCI through Facebook Insights, and collected manually from Mercy Corps. The date range was from November 15, 2016 through April 15, 2017, creating a total sample size of 190 posts.

\section{Coding}

Coding schemes were developed to categorize both the text of each post and the content of the photo accompanying it. As a first step in conducting analysis of this kind, the data was coded manually rather than developing and implementing algorithms for computerized coding. This method therefore represents an example of coding that could be used for this kind of analysis and could hopefully be replicated using algorithms in order to conduct the analysis on a larger scale.

\section{Text Coding}

The Information-Community-Action coding scheme, originally created by Lovejoy and Saxton in 2012 for a content analysis identifying the functions of nonprofit Twitter posts, was adopted and modified for this study to categorize the text portions of the photo posts. As Twitter's functionality is very different from that of Facebook, particularly with regard to its 140-character limit, there are some differences also in the message strategies utilized on each platform. The scheme was therefore adapted to accommodate these differences. In instances where more than one function appeared in the text, the primary function was used to categorize it. See Appendix A for examples and frequency distribution.

The Information category describes posts that contain any kind of information that is relevant to the organization's stakeholders. In the original study, Information was a single category that encompassed all types of informational posts. In this study, however, this category has been broken down into seven subcategories: Activity, in which the post describes a specific activity taking place in the area served (a more short-term and immediate focus); Program or campaign, where the post 
PHOTOS

describes, more generally, an ongoing program or campaign (e.g., in a certain country or region, toward a specific goal, etc.) that exemplifies their organizational mission; Organizational mission/values, which is more broad than the latter two and of a longer-term focus; and four other categories of Event bighlight, Facts, News, and Other.

Posts within the Community category are intended to promote community-building and to create dialogue between the organization and its stakeholders. Two subcategories used in this study were taken directly from the original study: Acknowledgement of current \& local events and Giving thanks. The following additional subcategories were added: Volunteer/member story/highlight, in which a volunteer or member of the organization shares a specific or overall experience they had while working with the organization (told either through their own words or in the third person); Local story/ highlight, where the story or highlight is instead from the perspective of an individual living in a community served by the organization; Quote, being a direct quotation from either of the latter parties, but a short statement rather than a full story; Shout-out, where the post gives recognition, praise or thanks to a relevant third party organization or business; and Greeting.

The final category, Action, consists of posts that urge followers to get involved in some way that would either benefit the organization directly or would contribute to supporting a cause. The following subcategories were adopted from the original study: Promotion of an event; Donation appeal; Call for volunteers/employees; Lobbying \& advocacy; and Learn how to help. A sixth subcategory, called Share this post, was added in this study.

\section{Photo Coding}

The photos accompanying the text of the posts were categorized based on their content or subject matter. The following seven categories were used: Landscape; Informational, where a photo is included in the image but an infographic or informational text (e.g., statistics, event details) is the focus of the image; Volunteer(s)/member(s) in action; Individual portrait, where one single person (either a 
PHOTOS

local or a volunteer or member of the organization) is featured prominently; Group photo, where the main subject matter is two or more people, whether they are locals, a mix of locals and volunteers/members, or just volunteers/members; Portrait/quote combination, where an individual or group portrait is accompanied by a quote typewritten over the photo; Scene, which differs from previous categories in that it is usually candid and possibly shows movement, and often has a more dramatic or emotional tone; and Other, encompassing any other kinds of subject matter where generally there are no human subjects or the focus is not on a human subject (e.g., food, tools, etc.). See Appendix B for examples and frequency distribution.

\section{Analysis}

Because of the varying sizes of the three organizations, an individual analysis was conducted for each page. The goal of the analysis was to determine (1) if there were certain combinations of photo content and text functions that were the most effective in provoking engagements and (2) if there were strategies that worked best for each specific text function, particularly regarding the photos accompanying them. The analysis focused on total engagements, inclusive of the combined numbers of reactions, comments and shares. The number of total engagements as a percentage of the page's followers was also used as a metric of comparison between organizations and between text function and photo content categories (the assumption being that the number of followers stayed the same over the time period of the data set).

The first analysis involved simply identifying the top post on each organization's page. Then, averages in total engagements were taken for each general category and subcategory of the text functions and the top performing categories were identified. The same was done for the photo content categories. Finally, the top posts in each text function subcategory were isolated for each page in order to identify any common characteristics. 


\section{RESULTS}

The following chart shows the top performing post from each page and how it was coded. The text function of both PCI's and Mercy Corps' top posts was the action-oriented Donation appeal, while an informational Activity message was the category of JIA's top post. The type of photo content varied between the three. They each performed similarly when considering total engagements as a percentage of followers, with each one generating engagement from about $4 \%$ of their followers.

Top Posts

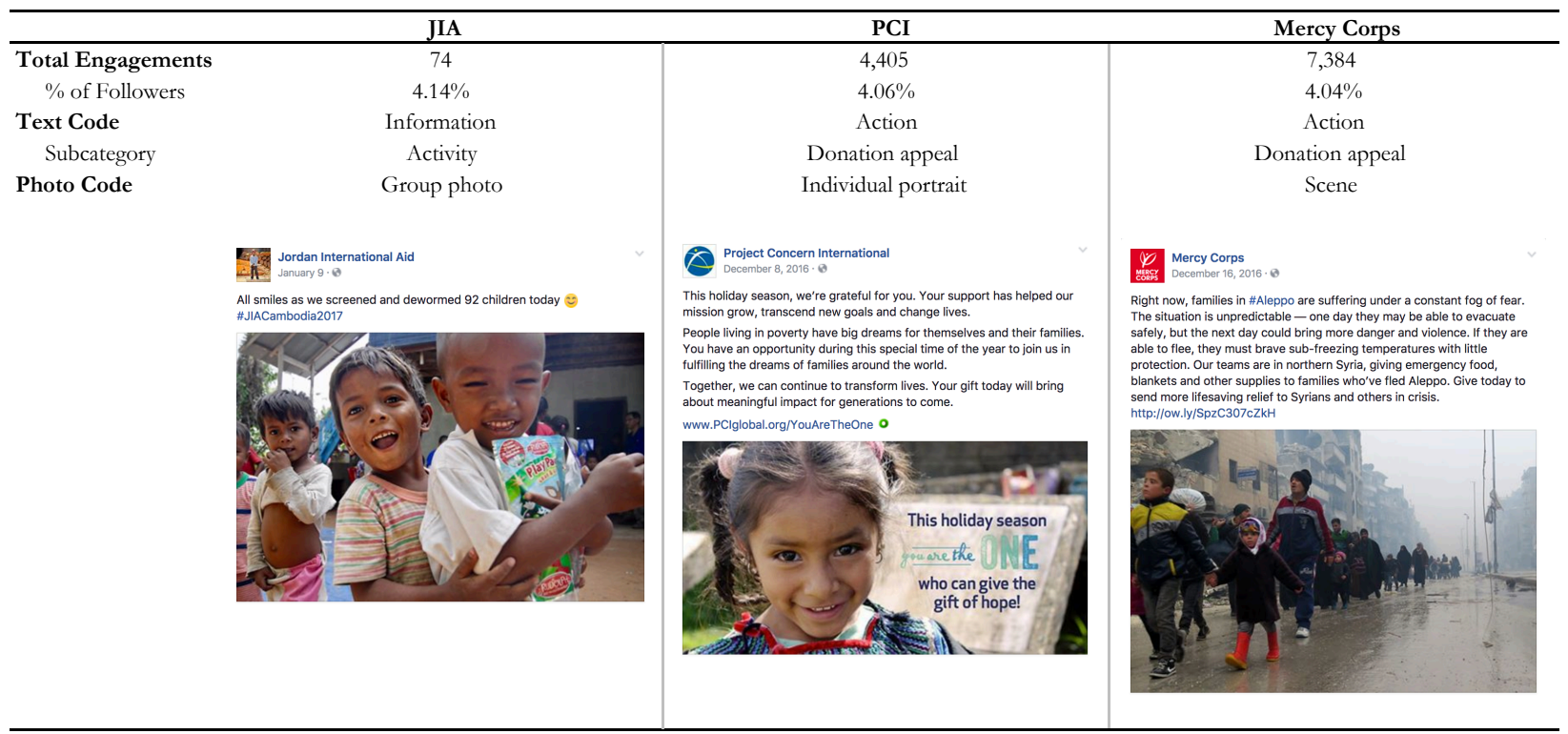

JIA's top performing category was Information, with the subcategory Activity generating the most engagements. However, the data is skewed due to the smaller sample size of posts from this organization, as the Activity subcategory represents only one post and was the same as their top post overall. The runner-up subcategory for JIA was Call for volunteers/employees. When looking at PCI and Mercy Corps, both organizations have their top category and subcategory in common; Action posts had significantly more engagements on average than the other two categories. For both, the best performing subcategory was Donation appeal. Volunteer/member highlight/story ranked in the top three 
PHOTOS

for JIA and PCI, but not for Mercy Corps. Appendix C charts these categories and highlights the top performers.

As for photo content, $\operatorname{Volunteer}(s) /$ member(s) in action was the top performing category for JIA, and ranked in the top three for all of the organizations. For both PCI and Mercy Corps, Individual Portrait was the top performing category. Group photo was the runner-up category for both JIA and PCI; for Mercy Corps, Informational images were a very close second. Appendix D charts these categories and highlights the best performers.

Each organization's best performing post information for each text function subcategory is shown in Appendices E, F, and G. Group photos were the most common among the top performing posts $(n=14)$, while photos within the Individual portrait and Scene categories were tied in second $(n=8)$. Photos categorized as Informational, Volunteer(s)/member(s) in action, and Portrait/quote combination were also used in the top-ranking posts (see Appendix $\mathrm{H}$ ). However, when assessed on a basis of total engagements generated by each category (which does not account for the different numbers of followers of each page), photos categorized as Scene had by far the most engagements, with Individual portrait following in second (see Appendix I).

\section{Discussion \& ConClusions}

Because of the small sample size, the results may not be statistically significant for drawing many generalized conclusions, though there are a few notable key findings.

Regarding the various text functions, it was found that Community posts were used the most commonly $(n=83 ; 43.68 \%)$, which contrasts with previous research using the Information-CommunityAction model that has found Information posts to be the most common on both Twitter and Facebook. However, while Action posts were used least frequently $(n=49 ; 25.79 \%)$, these posts 
were, overall, the top performers in terms of total engagements by a significant degree (see Appendix C). The first conclusion is, therefore, that action-oriented photo posts may have greater potential to provoke engagements from a page's followers.

Existing research on nonprofit social media pages has not yet conducted content analyses specifically of photos posted by these organizations. This study found that, among the three organizations, photos under the category of Individual portrait were the most commonly used $(n=64$; $33.68 \%$ ), while Group photos $(n=57 ; 30 \%)$ were a close runner-up. Scene $(n=39 ; 20.53 \%)$ photos were also used frequently, with those in the other categories being used much less commonly (see Appendix B). Not only were the Individual portrait photos the most commonly used, but overall, they had the most total engagements. Group photo posts also had significant engagement levels, and engagements on photos categorized as $V$ olunteer $(s) /$ member $(s)$ in action are also notable, since they ranked highly for all three organizations (see Appendix D). From these findings, the second conclusion can be made that Individual portraits, Groupphotos, and Volunteer(s)/member(s) in action photos may be considered effective in provoking engagement from followers. Overall, these are possible insights into the kind of content that resonates the most with the audience of nonprofit Facebook pages.

\section{LiMitATIONS \& FURTHER RESEARCH}

The most significant limitation of this study was the small sample size. A small sample size was used in part due to time constraints, since coding had to be completed manually and analyses were conducted individually for each organization. The time frame of the data collected also contributed to this limitation. Additionally, the time constraints and manual coding method limited the number of factors that were included in the analysis. 
For future research, coding the posts using computer algorithms would be the optimal method. Such a method would allow for analysis to be conducted on a much larger scale, using a sample size that includes more organizations and a longer time frame. A larger sample size of posts would result in more statistically meaningful results that could be better generalized across organizations. It would also create a wider and more varied range of text functions and types of photo content utilized, whereas in this study, there was only one instance in certain categories. One category, Event Highlight, was included despite having no instances across the three organization's pages. This is an issue that likely would not occur with a larger sample size.

If conducted on a larger scale, the number of followers of each organization's page would need to be addressed, possibly by using a weighting system, so that those with smaller followings are properly accounted for. However, even on a larger scale, it is likely best to remain within a single field of concentration for each analysis regarding the type of nonprofit, as was done in this study. Otherwise, the results and conclusions are more difficult to standardize, since nonprofits of varying types tend to use different strategies due to their respective organizational missions, values and goals.

Only a select group of factors considered to be the most significant were used in this study. Assessing the tone of the text portion of the posts is possible through text mining, which can be conducted using coding for computerized analysis, and would therefore be applicable for a largescale study. Similarly, it is possible to analyze the tone of photos when human subjects are included through certain facial analysis methods (e.g., Anderson \& Saxton, 2016). The influence of the inclusion of hashtags on engagement levels has not been widely studied, but would potentially be a relevant factor to address. Artistic qualities of photos (e.g., colors, composition) may also affect engagement. The use of certain tactics, such as including a link or a call to action, could also be considered. 
PHOTOS

There were a few aspects of this study that may have resulted in skewed results, and should be noted. The first was the disproportionate followings of the three organizations' pages. This was accounted for when observing the number of engagements as a percentage of followers in the analyses. However, there were instances where JIA's results were skewed in comparison to the other two, since there were fewer posts overall. Additionally, Facebook offers the option to "boost" specific posts for a paid fee. It is unknown if there were any posts for which the organizations used this function which, if used, would have likely affected engagement levels. Finally, the use of promotional or cause-related campaigns over a limited period of time affected the frequency of use of certain text functions and photo content. For instance, PCI ran two notable campaigns throughout the time frame of this study: (1) “25 Days of Empowered Women," where each post contained a Local story/ highlight in combination with generally either an Individual portrait or Group photo; and (2) "Giving Tuesday," where each post was a Donation appeal.

Because of the many limitations of this study, the main goal was to develop an example of a method for analyzing the relationship between photo posts and engagement levels that could be implemented on a larger scale for further research. This method could potentially be used to conduct content analyses on other social media platforms with photo sharing capabilities, such as Twitter and Instagram. It is also likely applicable to other fields of nonprofits than humanitarian aid and disaster relief. Through further research, better and more thorough evidence-based suggestions for effective photo post strategies for nonprofits can be developed. 


\section{REFERENCES}

Anderson, K. B., \& Saxton, G. D. (2016). Smiles, Babies, and Status Symbols: The Persuasive Effects of Image Choices in Small-Entrepreneur Crowdfunding Requests. International Journal of Communication, 10, 22. Retrieved from http://ijoc.org/index.php/ijoc/article/view/2829 $/ 1620$

Briones, R. L., Kuch, B., Liu, B. F., \& Jin, Y. (2010). Keeping up with the digital age: How the American Red Rross uses social media to build relationships. Public Relations Review, 37(1), 37-43. doi:10.1016/j.pubrev.2010.12.006

Campbell, D. A., Lambright, K. T., \& Wells, C. J. (2014). Looking for friends, fans, and followers? Social media use in public and nonprofit human services. Public Administration Review, 74(5), 655-663. doi:10.1111/puar.12261

Cho, M., \& Schweickart T. L. (2014). Nonprofits' use of Facebook: An examination of organizational message. Public Relations in the Nonprofit Sector: Theory and Practice. 281-295.

Cho, M., Schweickart, T., \& Haase, A. (2014). Public engagement with nonprofit organizations on Facebook. Public Relations Review, 40(3), 565-567. doi:10.1016/j.pubrev.2014.01.008

Davis, L., Rountree, M. M., \& Davis, J. A. (2016). Global Cause Awareness: Tracking Awareness Through Electronic Word of Mouth. Journal of Nonprofit \& Public Sector Marketing, 28(3), 252 272. doi:10.1080/10495142.2016.1206502

DiStaso, M. W., McCorkindale, T., \& Wright, D. K. (2011). How public relations executives perceive and measure the impact of social media in their organizations. Public Relations Review, 37(3), 325-328. doi:10.1016/j.pubrev.2011.06.005

Goldkind, L. (2015). Social Media and Social Service: Are Nonprofits Plugged In to the Digital Age? Journal Human Service Organizations: Management, Leadership \& Governance, 39(4), 380-396. doi:10.1080/23303131.2015.1053585

Guo, C., \& Saxton, G. D. (2013). Tweeting Social Change: How Social Media Are Changing Nonprofit Advocacy. Nonprofit and Voluntary Sector Quarterly, 43(1), 57-79. doi:10.1177/0899764012471585

Hanna, R., Rohm, A., \& Crittenden, V. L. (2009). We're all connected: The power of the social media ecosystem. Business Horizons, 54(3), 265-273. doi:10.1016/j.bushor.2011.01.007

Huang, Y.-C., Lin, Y.-P., \& Saxton, G. D. (2016). Give me a like: How HIV/AIDS nonprofit organizations can engage their audience on Facebook. AIDS Education and Prevention, 28(6), 539-556. doi:10.1521/aeap.2016.28.6.539

Kanter, B. and Fine, A. H. (2010). The Networked Nonprofit: Connecting with Social Media to Drive Change. San Francisco, CA: Jossey-Bass. 
Kanter, B., \& Paine, K. D. (2012). Measuring the networked nonprofit: Using data to change the world. San Francisco, CA: Jossey-Bass.

Lovejoy, K. and Saxton, G. D. (2012), Information, Community, and Action: How Nonprofit Organizations Use Social Media. Journal of Computer-Mediated Communication, 17: 337-353. doi:10.1111/j.1083-6101.2012.01576.x

Lovejoy, K., Waters, R. D., \& Saxton, G. D. (2012). Engaging stakeholders through Twitter: How nonprofit organizations are getting more out of 140 characters or less. Public Relations Review, 38(2), 313-318. doi:10.1016/j.pubrev.2012.01.005

Nah, S., \& Saxton, G. D. (2012). Modeling the adoption and use of social media by nonprofit organizations. New Media \& Society, 15(2), 294-313. doi:10.1177/1461444812452411

Paek, H.-J., Hove, T., Jung, Y., \& Cole, R. T. (2013). Engagement across three social media platforms: An exploratory study of a cause-related PR campaign. Public Relations Review, 39(5), 526-533. doi:10.1016/j.pubrev.2013.09.013

Paulin, M., J. Ferguson, R., Jost, N., \& Fallu, J.-M. (2013). Motivating millennials to engage in charitable causes through social media. Journal of Service Management, 25(3), 334-348. doi:10.1108/josm-05-2013-0122

Saxton, G. D., \& Waters, R. D. (2014). What do Stakeholders Like on Facebook? Examining Public Reactions to Nonprofit Organizations' Informational, Promotional, and CommunityBuilding Messages. Journal of Public Relations Research, 26(3), 280-299. doi:10.1080/1062726x.2014.908721

Waters, R. D., Burnett, E., Lamm, A., \& Lucas, J. (2009). Engaging stakeholders through social networking: How nonprofit organizations are using Facebook. Public Relations Review, 35(2), 102-106. doi:10.1016/j.pubrev.2009.01.006

Waters, R. D., \& Feneley, K. L. (2013). Virtual stewardship in the age of new media: Have nonprofit organizations' moved beyond web 1.0 strategies? International Journal of Nonprofit and Voluntary Sector Marketing, 18(3), 216-230. doi:10.1002/nvsm.1469

Waters, R. D., \& Jamal, J. Y. (2011). Tweet, tweet, tweet: A content analysis of nonprofit organizations' Twitter updates. Public Relations Review, 37(3), 321-324. doi:10.1016/j.pubrev.2011.03.002

Waters, R. D., \& Jones, P. M. (2011). Using video to build an organization's identity and brand: A content analysis of nonprofit organizations' YouTube videos. Journal of Nonprofit \& Public Sector Marketing, 23(3), 248-268. doi:10.1080/10495142.2011.594779 


\section{APPENDIX}

\section{Appendix A}

\section{Text Function}

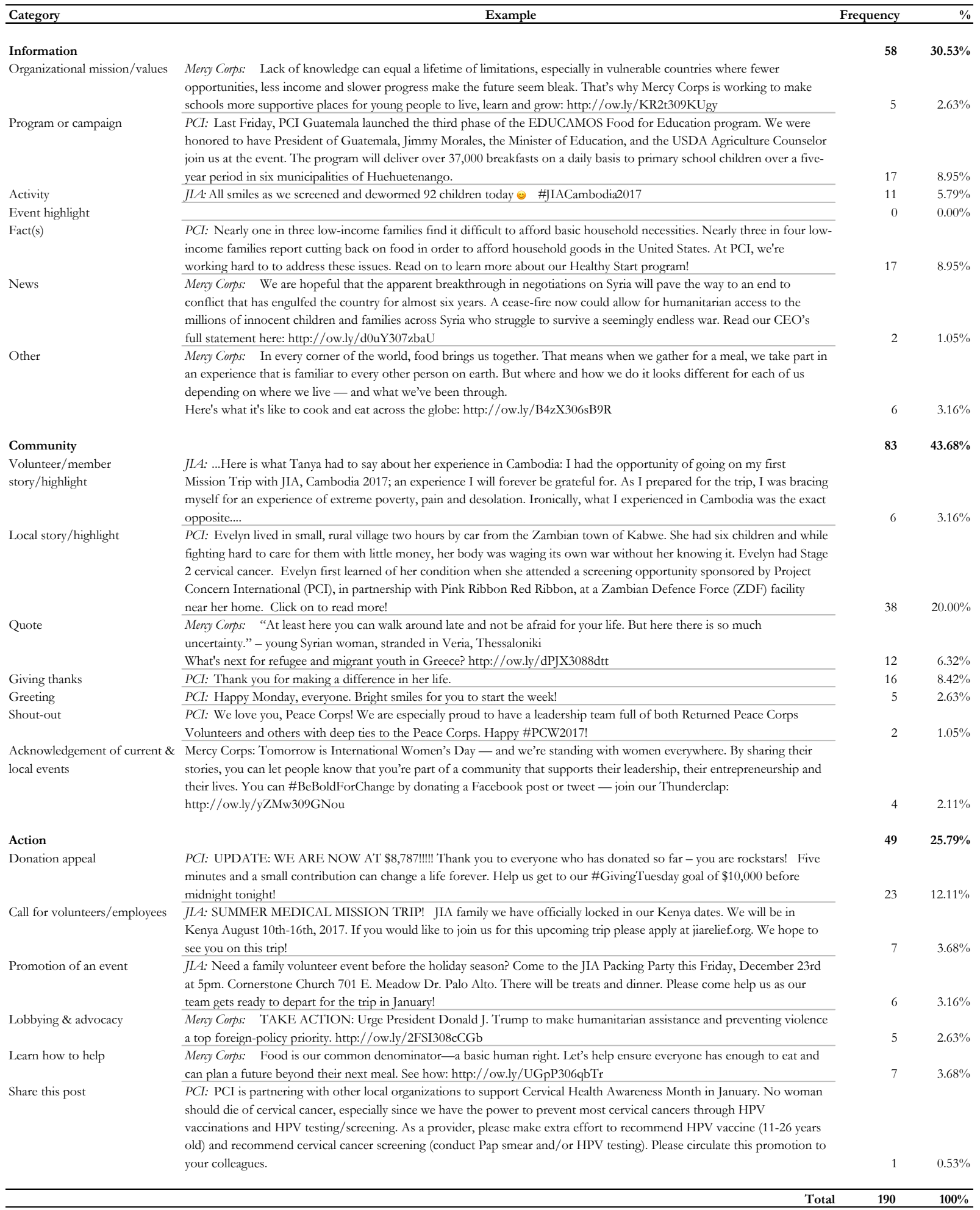


PHOTOS

\section{Appendix B}

Photo Content

\begin{tabular}{llrr}
\hline Category & Example & Frequency & $\mathbf{\%}$ \\
\hline Individual portrait & Figure 1 & 64 & $33.68 \%$ \\
Group photo & Figure 2 & 57 & $30.00 \%$ \\
Portrait/quote combination & Figure 3 & 5 & $2.63 \%$ \\
Volunteer(s)/member(s) in action & Figure 4 & 11 & $5.79 \%$ \\
Scene & Figure 5 & 39 & $20.53 \%$ \\
Informational & Figure 6 & 11 & $5.79 \%$ \\
Landscape & Figure 7 & 1 & $0.53 \%$ \\
Other & Figure 8 & 2 & $1.05 \%$ \\
\hline & Total & $\mathbf{1 9 0}$ & $\mathbf{1 0 0 . 0 0 \%}$ \\
\hline
\end{tabular}

Figure 1 (Mercy Corps)

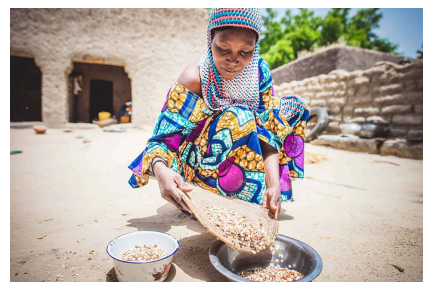

Figure 3 (Mercy Corps)

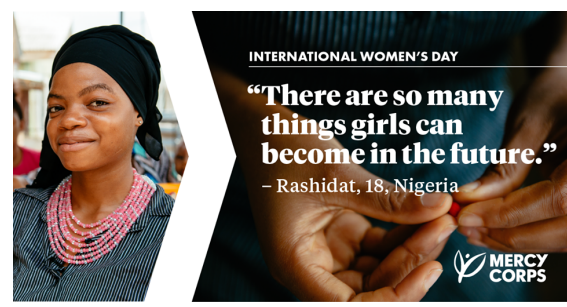

Figure 5 (Mercy Corps)

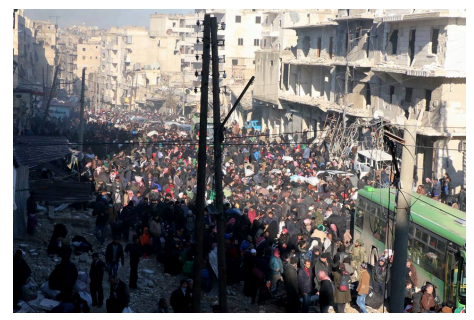

Figure 7 (JIA)

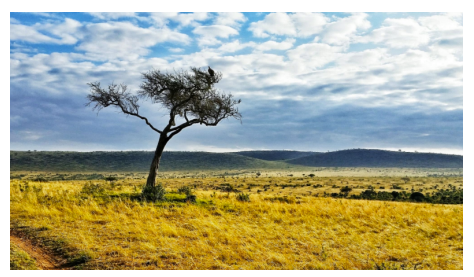

Figure 2 (IIA)

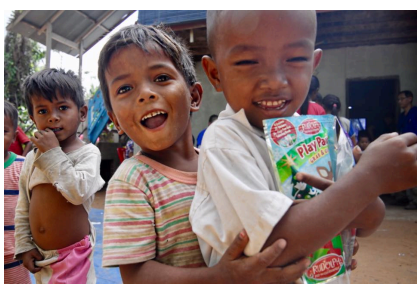

Figure 4 (JIA)

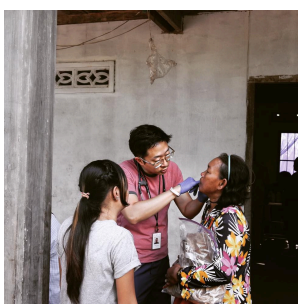

Figure 6 (Mercy Corps)

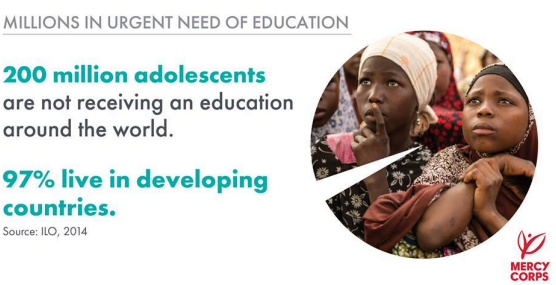

Figure 8 (PCI)

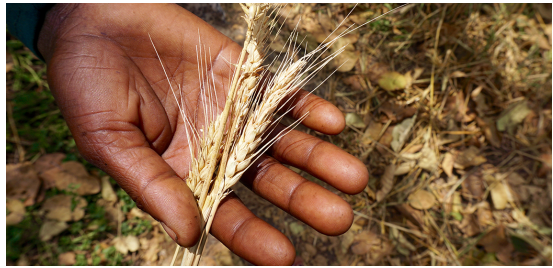


INCREASING ENGAGEMENT ON NONPROFIT FACEBOOK PAGES THROUGH

PHOTOS

\section{Appendix C}

Average Engagements by Text Function

\begin{tabular}{|c|c|c|c|c|c|c|}
\hline & \multicolumn{2}{|l|}{ JIA } & \multicolumn{2}{|l|}{ PCI } & \multicolumn{2}{|c|}{ Mercy Corps } \\
\hline & Avg. Total Engagements & $\%$ of Followers & Avg. Total Engagements & $\%$ of Followers & Avg. Total Engagements & $\%$ of Followers \\
\hline Information & 45.33 & $4.08 \%$ & 69.44 & $0.06 \%$ & 160.54 & $0.09 \%$ \\
\hline Organizational mission/values & --- & --- & 47.5 & $0.04 \%$ & 64.67 & $0.04 \%$ \\
\hline Program or campaign & --- & --- & 76.5 & $0.07 \%$ & 105.78 & $0.06 \%$ \\
\hline Activity & 45.33 & $4.08 \%$ & 80 & $0.07 \%$ & 339.71 & $0.19 \%$ \\
\hline Event highlight & --- & --- & --- & --- & --- & --- \\
\hline Fact(s) & --- & --- & 54.57 & $0.05 \%$ & 111.8 & $0.06 \%$ \\
\hline News & --- & --- & --- & --- & 164 & $0.09 \%$ \\
\hline Other & --- & --- & --- & --- & 188.67 & $0.10 \%$ \\
\hline Community & 19.67 & $1.10 \%$ & 73.64 & $0.07 \%$ & 135.13 & $0.07 \%$ \\
\hline Volunteer/member story/highlight & 23 & $1.29 \%$ & 284.25 & $0.26 \%$ & 108 & $0.06 \%$ \\
\hline Local story/highlight & --- & --- & 46.81 & $0.04 \%$ & 98.14 & $0.05 \%$ \\
\hline Quote & --- & --- & 126 & $0.12 \%$ & 160.82 & $0.09 \%$ \\
\hline Giving thanks & 13 & $0.73 \%$ & 61 & $0.06 \%$ & 102 & $0.06 \%$ \\
\hline Greeting & --- & --- & 67.67 & $0.06 \%$ & 244 & $0.13 \%$ \\
\hline Shout-out & --- & --- & 113 & $0.10 \%$ & 167 & $0.09 \%$ \\
\hline Acknowledgement of current \& local events & --- & --- & 92.33 & $0.09 \%$ & 63 & $0.03 \%$ \\
\hline Action & 18.25 & $1.02 \%$ & 430.8 & $0.40 \%$ & 1080.22 & $0.59 \%$ \\
\hline Donation appeal & 12 & $0.67 \%$ & 633 & $0.58 \%$ & 2219.89 & $1.21 \%$ \\
\hline Call for volunteers/employees & 23.5 & $1.31 \%$ & 59 & $0.05 \%$ & --- & --- \\
\hline Promotion of an event & 14 & $0.78 \%$ & 65 & $0.06 \%$ & 302.75 & $0.17 \%$ \\
\hline Lobbying \& advocacy & --- & -- & --- & --- & 574.2 & $0.31 \%$ \\
\hline Learn how to help & --- & --- & --- & --- & 143 & $0.08 \%$ \\
\hline Share this post & --- & --- & 27 & $0.02 \%$ & --- & --- \\
\hline
\end{tabular}

Top performing general category

Top performing subcategory

2nd best performing subcategory

3rd best performing subcategory 
PHOTOS

\section{Appendix D}

Average Engagements by Photo Content

\begin{tabular}{|c|c|c|c|c|c|c|}
\hline & \multicolumn{2}{|l|}{ JIA } & \multicolumn{2}{|l|}{ PCI } & \multicolumn{2}{|c|}{ Mercy Corps } \\
\hline & Avg. Total Engagements & $\%$ of Followers & Avg. Total Engagements & $\%$ of Followers & Avg. Total Engagements & $\%$ of Followers \\
\hline Individual portrait & --- & --- & 186.21 & $0.17 \%$ & 509.5 & $0.28 \%$ \\
\hline Group photo & 29 & $1.62 \%$ & 153.53 & $0.14 \%$ & 176.88 & $0.10 \%$ \\
\hline Portrait/quote combination & --- & --- & --- & --- & 151 & $0.08 \%$ \\
\hline Volunteer(s)/member(s) in action & 31 & $1.73 \%$ & 76 & $0.07 \%$ & 258 & $0.14 \%$ \\
\hline Scene & --- & --- & 75.14 & $0.07 \%$ & 502.34 & $0.27 \%$ \\
\hline Informational & 24.5 & $1.37 \%$ & 41.67 & $0.04 \%$ & 88 & $0.05 \%$ \\
\hline Landscape & 10 & $0.56 \%$ & --- & --- & --- & --- \\
\hline Other & --- & --- & 30.5 & $0.03 \%$ & --- & --- \\
\hline
\end{tabular}

Top performing category

2nd best performing category

3 rd best performing category 
PHOTOS

\section{Appendix E}

\section{Best Performers: JIA}

\begin{tabular}{|c|c|c|c|}
\hline & & JIA & \\
\hline & Total Engagements & $\%$ of Followers & Photo Code \\
\hline \multicolumn{4}{|l|}{ Information } \\
\hline Organizational mission/values & --- & --- & --- \\
\hline Program or campaign & --- & --- & --- \\
\hline Activity & 74 & $4.08 \%$ & Group photo \\
\hline Event highlight & --- & --- & --- \\
\hline Fact(s) & --- & --- & --- \\
\hline News & --- & --- & --- \\
\hline Other & --- & --- & --- \\
\hline \multicolumn{4}{|l|}{ Community } \\
\hline Volunteer/member story/highlight & 30 & $1.68 \%$ & Volunteer(s)/member(s) in action \\
\hline Local story/highlight & --- & --- & --- \\
\hline Quote & --- & --- & --- \\
\hline Giving thanks & 13 & $0.73 \%$ & Group photo \\
\hline Greeting & --- & --- & --- \\
\hline Shout-out & --- & --- & --- \\
\hline Acknowledgement of current \& local events & --- & --- & --- \\
\hline \multicolumn{4}{|l|}{ Action } \\
\hline Donation appeal & 12 & $0.67 \%$ & Informational \\
\hline Call for volunteers/employees & 37 & $2.07 \%$ & Informational \\
\hline Promotion of an event & 14 & $0.78 \%$ & Group photo \\
\hline Lobbying \& advocacy & --- & --- & --- \\
\hline Learn how to help & --- & --- & --- \\
\hline Share this post & --- & --- & --- \\
\hline
\end{tabular}


PHOTOS

\section{Appendix F}

\section{Best Performers: PCI}

\begin{tabular}{|c|c|c|c|}
\hline & & PCI & \\
\hline & Total Engagements & $\%$ of Followers & Photo Code \\
\hline \multicolumn{4}{|l|}{ Information } \\
\hline Organizational mission/values & 48 & $0.04 \%$ & Individual portrait \\
\hline Program or campaign & 122 & $0.11 \%$ & Group photo \\
\hline Activity & 80 & $0.07 \%$ & Group photo \\
\hline Event highlight & --- & --- & --- \\
\hline Fact(s) & 106 & $0.10 \%$ & Individual portrait \\
\hline News & --- & --- & --- \\
\hline Other & --- & --- & --- \\
\hline \multicolumn{4}{|l|}{ Community } \\
\hline Volunteer/member story/highlight & 779 & $0.72 \%$ & Individual portrait \\
\hline Local story/highlight & 128 & $0.12 \%$ & Group photo \\
\hline Quote & 126 & $0.12 \%$ & Scene \\
\hline Giving thanks & 112 & $0.10 \%$ & Individual portrait \\
\hline Greeting & 132 & $0.12 \%$ & Group photo \\
\hline Shout-out & 113 & $0.10 \%$ & Group photo \\
\hline Acknowledgement of current \& local events & 143 & $0.13 \%$ & Individual portrait \\
\hline \multicolumn{4}{|l|}{ Action } \\
\hline Donation appeal & 4,405 & $4.06 \%$ & Individual portrait \\
\hline Call for volunteers/employees & 105 & $0.10 \%$ & Group photo \\
\hline Promotion of an event & 65 & $0.06 \%$ & Informational \\
\hline Lobbying \& advocacy & --- & --- & --- \\
\hline Learn how to help & --- & --- & --- \\
\hline Share this post & 27 & $0.02 \%$ & Informational \\
\hline
\end{tabular}


PHOTOS

\section{Appendix G}

Best Performers: Mercy Corps

\begin{tabular}{|c|c|c|c|}
\hline & \multicolumn{3}{|c|}{ Mercy Corps } \\
\hline & Total Engagements & $\%$ of Followers & Photo Code \\
\hline \multicolumn{4}{|l|}{ Information } \\
\hline Organizational mission/values & 74 & $0.04 \%$ & Informational \\
\hline Program or campaign & 189 & $0.10 \%$ & Group photo \\
\hline Activity & 778 & $0.43 \%$ & Scene \\
\hline Event highlight & --- & --- & --- \\
\hline Fact(s) & 163 & $0.09 \%$ & Scene \\
\hline News & 197 & $0.11 \%$ & Scene \\
\hline Other & 650 & $0.36 \%$ & Volunteer(s)/member(s) in action \\
\hline \multicolumn{4}{|l|}{ Community } \\
\hline Volunteer/member story/highlight & 108 & $0.06 \%$ & Scene \\
\hline Local story/highlight & 132 & $0.07 \%$ & Group photo \\
\hline Quote & 421 & $0.23 \%$ & Individual portrait \\
\hline Giving thanks & 138 & $0.08 \%$ & Group photo \\
\hline Greeting & 256 & $0.14 \%$ & Individual portrait \\
\hline Shout-out & 167 & $0.09 \%$ & Group photo \\
\hline Acknowledgement of current \& local events & 63 & $0.03 \%$ & Group photo \\
\hline \multicolumn{4}{|l|}{ Action } \\
\hline Donation appeal & 7,384 & $4.04 \%$ & Scene \\
\hline Call for volunteers/employees & --- & --- & --- \\
\hline Promotion of an event & 881 & $0.48 \%$ & Scene \\
\hline Lobbying \& advocacy & 2,049 & $1.12 \%$ & Scene \\
\hline Learn how to help & 427 & $0.23 \%$ & Portrait/quote \\
\hline Share this post & --- & --- & --- \\
\hline
\end{tabular}


PHOTOS

\section{Appendix $\mathbf{H}$}

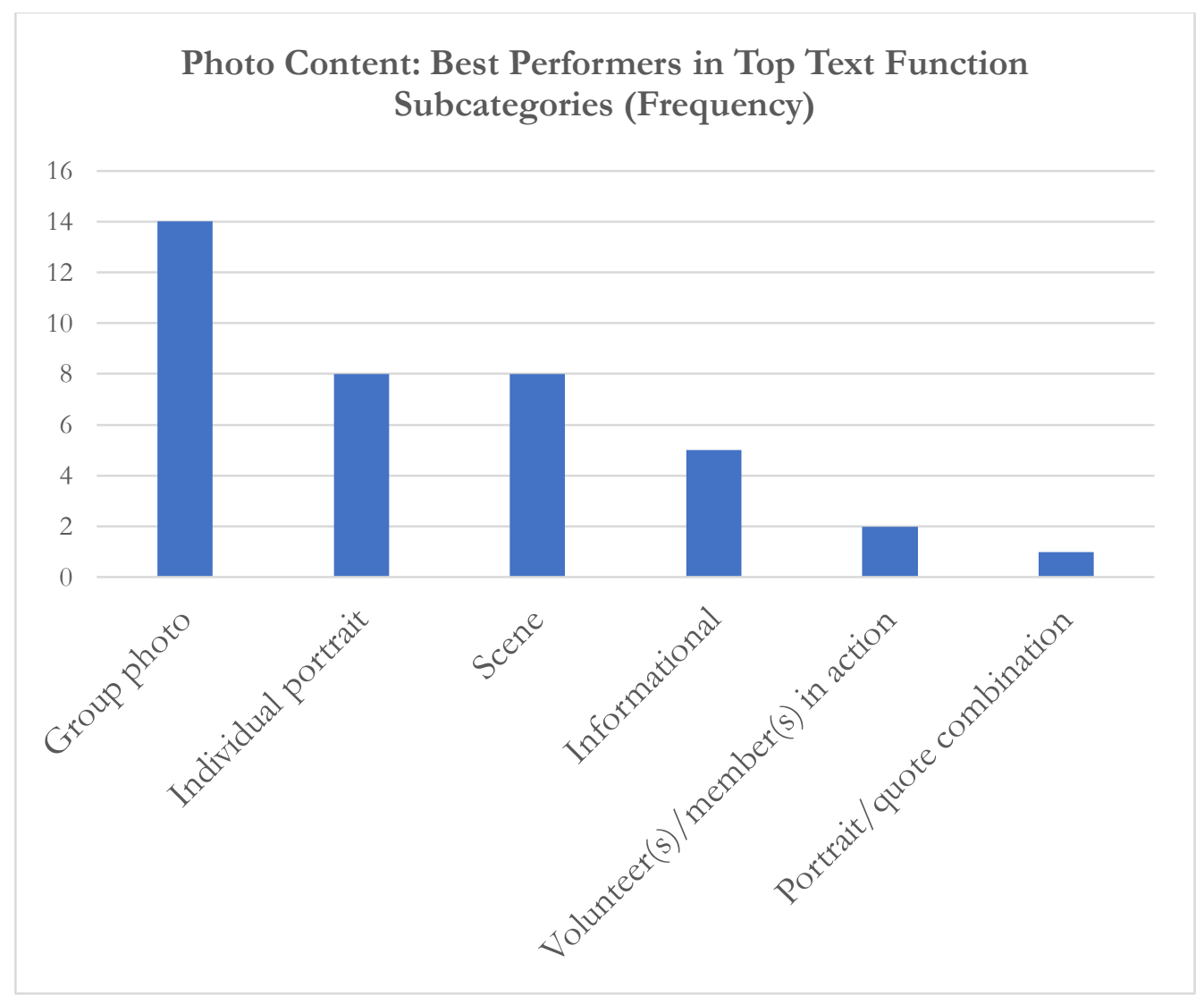




\section{PHOTOS}

\section{Appendix I}

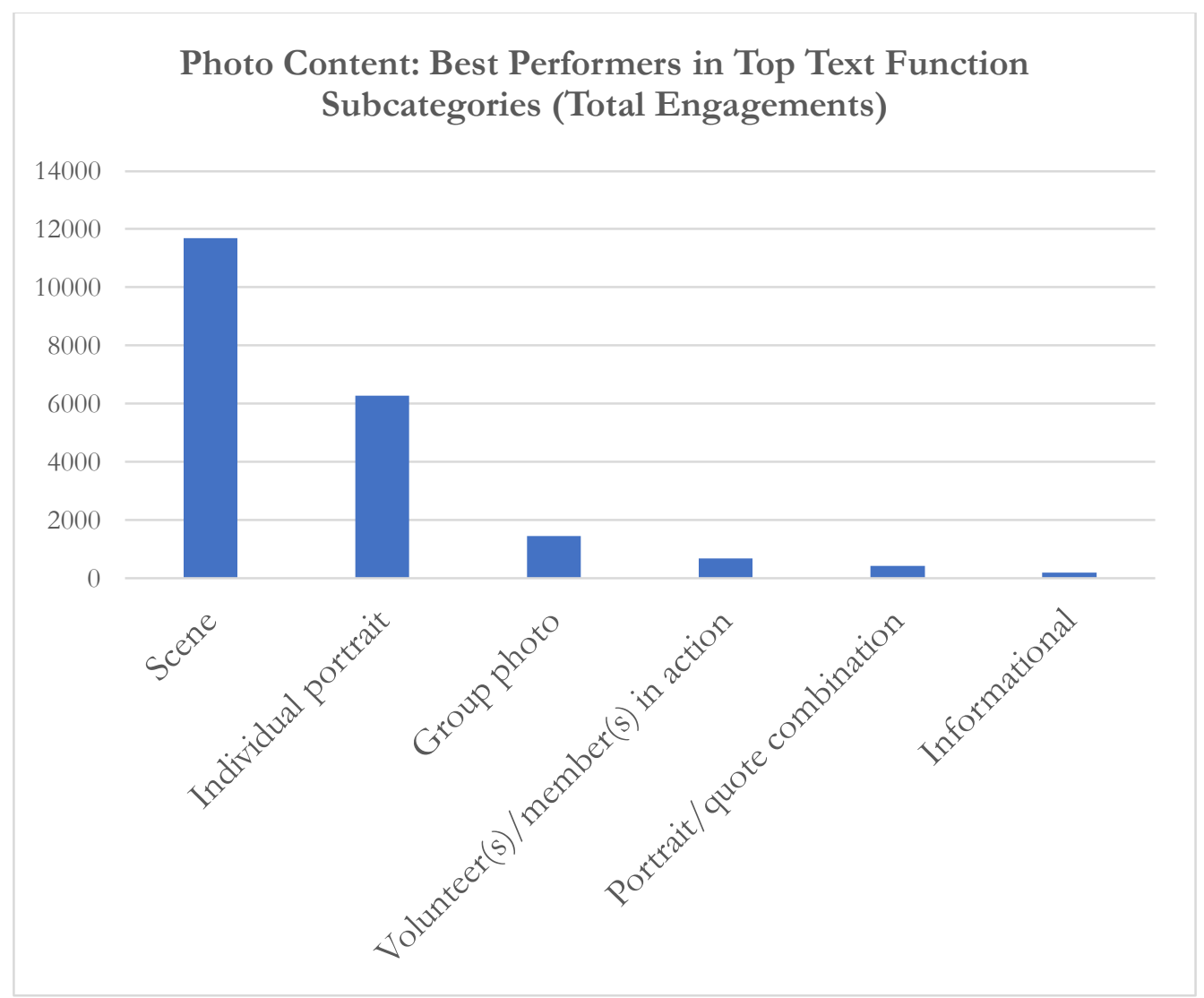

